up well, leaving only the state of chronic bronchitis, from which she had latterly suffered. Of course, her strength was much lowered by the attack, and she never thoroughly regained it. Some three weeks before death, her brain began to show evidence of her exhaustion, by its failing power, drowsiness, etc., although her mind, up to this time, had remained remarkably clear. Five days before her death she had a convulsive seizure; and, although this passed off, she gradually became less and less clear, taking less nourishment, and finally, as it were, slept away. Her marvellous power of vitality was shown by her so thoroughly throwing off such a severe pneumonia, which would have killed many a far younger woman."

Miss Hastings was a typical instance of an aged person : of long. lived family, of strong constitution, all the organs being strong and well balanced; with good appetite and digestion, but a moderate or small eater, taking little alcohol, and not much meat; with regular action of bowels ; of spare frame, robust, energetic, and of benevolent, happy disposition ; of good ability, with usually good health ; taking a fair amount of out-of-door exercise ; having no illness till near the close of her life; and, at a very advanced age, showing renarkable power of recovering from severe attacks-bronchitis, erysipelas, pneumonia,-thus resisting the savage onslaughts of disease, and yielding at last to the slow, steady, orderly advancing developmental processes by which the natural termination of life is brought about. (See remarks on this, in my address on Old Age, in this JournaL, May 9 th, 1885 .

P.S. - A table of the reports I have received respecting centenarians is preparing for publication in the Journal ; indeed, it is in the press. I I shall be glad, however, still to send forms to any members of the profession who ean fill them up from centenarians with whom they are acquainted, and shall be able to add them to the table if they are returned to me quickly.

\section{NOTES UPON LANOLIN.}

By W ALTER G. SM.ITH, M.D.,

Physician to Sir Patrick Dun's Hospital ; King's' Professor of Materia Medica School of Physic, Trinity College, Dublin.

THIs substance, for the introduction of which into therapeutics we are indebted to the distinguished Professor of Pharmacology in the University of Berlin, ${ }^{1}$ is a valuable addition to our resources, and doubtless will come into general use. It is a very interesting body from more than one point of view.

1. It is a neutral fatty salt of cholesterin; that is, cholesterin (a monatomic alcohol) takes the place of glycerin, which is the radical of ordinary fats.

2. Liebreich has demonstrated the wide diffusion of this cholesterinfat throughout the animal kingdom.

3. It is not a secretion arising from sobaceous or other glands, but is a product of retrograde metamorphosis of keratin or keratinyielding tissues.

Liebreich suggested, but was not prepared to prove, that cholesterin-fat was present in the keratin-cells, or in the granular layer of the epidermis from which the keratin-cells are derived ; but Lewin (Berl. klin. Woch., 1886) has since shown that its presence can be demunstrated micro-chemically in the granular layer of the skin by Liebermann's test (acetic anhydride and sulphuric acid).

4. Lanolin commends itself, pharmaceutically, as a basis for ointments.

Shortly after reading Liebreich's paper, I obtained some lanolin from Mr. Martindale, and began to prescribe it. Within the last two and a half months, I have employed it frequently (over seventy times), and feel assured that it possesses properties which deserve attention from all practitioners. These properties are the following.

$a$. It is capable of absorbing and intimately blending with large amounts of water, standing thus in marked contrast to popular notions of the mutual relations of water and fats." The lanolin of commerce is a combination of neutral cholesterin-fat with about 30 per cent. of water.

b. It is neutral to test-paper, is not liable to rancidity, and is not easily saponified by alkalies.

c. It is miscible with glycerin, unlike other fats.

d. It rapidly, and in a remarkable degree, possesses the power of penetrating the epidermis.

e. Hence lanolin greatly facilitates the absorption through the skin

1 The original paper was published in Berti klin. Wock., No. 47, 1885, and in the BRITrse MEDtoAL"JouRnaL, January 16th, 1886; and some further "ObBervations " in the JOURNAL, February 13th, 1886, give a number of useful formulæ of drugs mixed with it. So marked is this, that, with poisonous drugs, such as the toxic alkaloids, less (about half) than the usual proportion should be preseribed in ointments. The vaselins and paraffins hinder, rather than favour, the passage of drugs into the skin.

I will now briefly mention two or three cases in illustration of the uses of lanolin.

Ecrema.-Captain -, a patient of Dr. Gilbert Lynch, consulted me while on a visit in Dublin. He was a corpulent man; with varicose veins in both legs, and was much troubled by an angry outbreak of oczema rubrum on the legs, on and off for two years. For this, he had had the best advice in London, but without very satisfactory results. When I saw him the leg was weeping, fiery red, and intolerably itchy. The following ointment was prescribed. Lanolini 3 xij'; adipis benz. $3 \mathrm{j}$; liq. plumbi subacet. fort. $\mathrm{m} \times \mathrm{xv}$; acidi carbol: 3 ss ; olei lavand. $\mathrm{m}$. Speedy improvement enisued; the itching was calmed; he was able to walk about in comfort, and in about three weeks was practically cured. Ethereal solution of nitrate of silver ( 20 grains to 1 oz.) was twice applied.

Psoriasis.-Miss G., aged 25, was sent up to me from Doneraile, County Cork. For fifteen years she had been subject to psoriasis, here and there; and in January, 1886, the disease suddenly deve. loped into an extensive eruption over the face, chest, back and limbs ; in fact, no part of the body was spared. She was oovered from head to foot with small circular scaly patches.

I first prescribed a lotion of soft soap, spirit, and carbolic acid, which smarted her. A few days afterwards, this lotion was applied to one limb, and ointment to the opposite limb (lanolin and lard, including pyrogallic acid 40 grains, and salicylic acid 20 grains, respectively, to the ounce). This ointment caused no irritation, and exercised a more favourable influence on the eruption. Progress; however, being rather slow, I substituted for the above ointment a lanolin and chrysarobin ointment (20 grains to 1 ounce). This pro: duced speedy and marked improvement. In a week there was a striking change for the better, and in a fortnight all infiltration and scaliness had vanished, and no trace of the eruption remained, except some brown pigmentary stains. White precipitate ointment was used on the face, and with good effect. Arsenic was given internally.

Rheumatic Exudation.-Miss F. was attacked, four years ago, with stiffiness and pain in the back of the neck. This gradually became worse, and, for some months, she suffered acute pain in the neck, especially upon movement. The head drooped down on the chest, she could not sit at table with comfort, and her life was becoming miserable. On each side of the cervical' spine, especially the left, there was an indurated ridge of thickening, apparently in and betwcen the muscles, and very tender to touch. She was given iodide of potassium and chloride of calcium internally, and was directed to rub in gently, but thoroughly, an ointment of lanolin and lard, containing fifteen grains of iodide of potassium, twenty grains of iodoform, and three grains of hydrochlorate of morphine to the ounce. Improvement was soon apparent, and steadily continued; and, in about three weeks, she could elevate and rotate the head freely, and with little pain, and the hard infiltration at the nape had greatly diminished. The degree of pliancy can: ferred on the skin was remarkable, and the effect of the ointment in alleviating the local discomfort was unquestionable. Hitherto, I had found little reason for faith in the efficacy of iodide of potassium applied externally.

I have also used lanolin in acne, and in some other affections; and, speaking generally, can confirm the statement of Professor Liebreich and Dr. Lassar (based on over 400 cases), that it does not cause irrita. tion of the skin. It is true that some cases of eczema were none the better, perhaps even aggravated, after the use of a lanolin-ointment ; but similar experience is not uncommon with divers modes of treatment in obstinate cases of this fickle disease, and lanolin is no cutaneous panacea. In ringworm of the head, I have not had sufficient time to judge fairly of its effects.

With chapped hands, its effects are extremely satisfactory, and several bad cases occurring among my friends during the recent severe weather were cured by a single inunction of lanolin. For this purpase, perhaps, siniple lanolin is the best to use, as it is rapidly incorporated into the skin. For general use, its stickiness should be counteracted by admixture with one-eighth or one-fourth of another fat (lard, castor-oil, etc.). A few minims of oil of lavender, or oil of encalyptus, will communicate an agreeable odour to the ointment.

Central London Throat and Ear Hospital. - The Committee gratefully acknowledge the receipt of a donation of $£ 20$ in aid of the Llewelyn Thomas Memorial Fund from Dr. Henry Foster Burnes, a former clinical assistant of the Institution. 